\title{
Coexistence of mycobacterial infections - Mycobacterium tuberculosis and Mycobacterium leprae - in Sri Lanka: a case series
}

B. S. D. P. Keragala', H. M. M. T. B. Herath" ${ }^{2 *}$, G. H. D. C. Janapriya', S. Vanitha', Thanushah Balendran', Thavarajah Janani ${ }^{1}$, T. S. Keragala ${ }^{3}$ and C. N. Gunasekera ${ }^{1}$

\begin{abstract}
Background: Leprosy is one of the oldest mycobacterial infections and tuberculosis is the most common mycobacterial infection with a higher degree of infectivity than leprosy. Although both diseases are prevalent in clusters in developing countries, simultaneous occurrence of them in an individual is a rare entity, even in an endemic setting.
\end{abstract}

Case presentation: We describe six cases of tuberculosis and leprosy coinfection: a 57-year-old Sinhalese woman, a 47-yearold Tamil woman, a 72-year-old Tamil man, a 59-year-old Sinhalese man, a 54-year-old Sinhalese man, and a 50-year-old Sinhalese man. In this case series, five patients had lepromatous leprosy and the majority of patients were men. Three patients were detected to have tuberculosis at the outset of treatment of leprosy, while two developed tuberculosis later and one had extrapulmonary tuberculosis 5 years before the diagnosis of leprosy. The latter developed pulmonary tuberculosis as a reactivation while on treatment for leprosy. A majority of our patients with pulmonary tuberculosis had positive Mantoux test, high erythrocyte sedimentation rate, radiological evidence, and acid-fast bacilli in sputum. Human immunodeficiency virus and diabetes were detected in one patient. One patient had rifampicin-resistant tuberculosis, while she was on monthly rifampicin therapy for leprosy.

Conclusion: An immunocompromised status, such as human immunodeficiency virus infection, diabetes, and immunosuppressive drugs, are risk factors for tuberculosis infection. The use of steroids in the treatment of leprosy may increase the susceptibility to develop tuberculosis. Development of rifampicin resistance secondary to monthly rifampicin in leprosy is a major concern in treating patients coinfected with tuberculosis. Despite the paucity of reports of coinfection, it is advisable to screen for tuberculosis in patients with leprosy, especially if there are respiratory or constitutional symptoms, high erythrocyte sedimentation rate, and abnormal chest $X$-ray. The fact is that positive Mantoux and QuantiFERON Gold tests and presence of acid-fast bacilli in sputum are misleading, chest X-ray evidence of active tuberculosis and positive tuberculosis cultures are important diagnostic clues for active tuberculosis infection in a patient with leprosy. This is important to avoid monthly rifampicin in patients with suspected coinfections, which may lead to development of drug resistance to tuberculosis treatment. Whether prolonged steroid therapy in leprosy is a risk factor for development of tuberculosis is still controversial.

Keywords: Tuberculosis, Leprosy, Coinfection, Case series

\footnotetext{
* Correspondence: Tharukaherath11@gmail.com

${ }^{2}$ Institute of Neurology, National Hospital of Sri Lanka, Colombo, Sri Lanka

Full list of author information is available at the end of the article
}

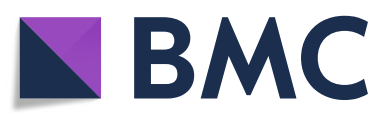

(c) The Author(s). 2020 Open Access This article is licensed under a Creative Commons Attribution 4.0 International License, which permits use, sharing, adaptation, distribution and reproduction in any medium or format, as long as you give appropriate credit to the original author(s) and the source, provide a link to the Creative Commons licence, and indicate if changes were made. The images or other third party material in this article are included in the article's Creative Commons licence, unless indicated otherwise in a credit line to the material. If material is not included in the article's Creative Commons licence and your intended use is not permitted by statutory regulation or exceeds the permitted use, you will need to obtain permission directly from the copyright holder. To view a copy of this licence, visit http://creativecommons.org/licenses/by/4.0/ The Creative Commons Public Domain Dedication waiver (http://creativecommons.org/publicdomain/zero/1.0/) applies to the data made available in this article, unless otherwise stated in a credit line to the data. 


\section{Introduction}

Tuberculosis (TB) is a multisystem disease and one of the most common infectious causes of deaths worldwide. Leprosy is an infectious disease that involves the skin and peripheral nerves. Both TB and leprosy are granulomatous infections caused by the intracellular Gram-positive aerobic acid-fast bacilli (AFB) Mycobacterium tuberculosis and Mycobacterium leprae, respectively. Clinical manifestations of both diseases vary according to the host's immune status and response. TB, at one pole, can present as miliary $\mathrm{TB}$, which is anergic and multibacillary and, at the other pole, as lupus vulgaris and verrucous TB, which are hyperergic and paucibacillary, while erythema induratum of Bazin is an immune-mediated hypersensitivity reaction for TB [1]. In leprosy, at one pole, tuberculoid leprosy represents a paucibacillary form and, at the other pole, lepromatous leprosy represents the multibacillary form [2]. Immunological reactions to leprosy manifest as lepra reactions that can occur before, during, or even years after completion of treatment.

Both are prevalent in clusters in developing countries; however, the simultaneous occurrence of both infections in an individual is rare even in endemic areas ( 0.02 per 100,000 population) [3]. Only a few case reports of the coexistence of $\mathrm{TB}$ and leprosy in the same patients are available in the literature. In this case series we describe six Sri Lankan patients who were infected with both TB and leprosy over a period of 7 years starting from 2012 and we briefly review the literature of coinfection.

\section{Case presentations}

\section{Case 1}

A 57-year-old Sinhalese woman presented to the dermatology unit of the National Hospital of Sri Lanka with extensive seborrheic dermatitis and tender facial induration (Fig. 1) of 1-year duration. She was a homemaker from an urban area with poor social background. She did not have diabetes or hypertension. She had received a Bacillus Calmette-Guérin (BCG) vaccination. She did not smoke tobacco or drink alcohol. A skin biopsy taken from indurated facial plaque revealed evidence of borderline tuberculoid leprosy with type 1 reaction. She did not have hypopigmented anesthetic patches or thickened peripheral nerves in the rest of her body. She was commenced on multibacillary treatment for leprosy. A year later, she developed fever, loss of appetite, loss of weight, and widespread skin abscesses all over her body. Her body mass index (BMI) was within normal range and the rest of the general examination was normal. A respiratory examination revealed bilateral (B/L) coarse crepitations; a neurological examination was normal. Her erythrocyte sedimentation rate (ESR) remained persistently elevated at more than $120 \mathrm{~mm} /$ hour. She had inflammatory shadows

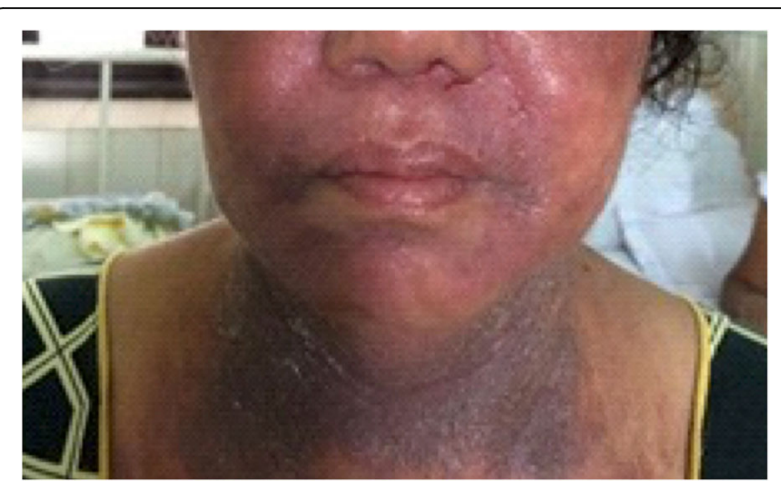

Fig. 1 Extensive seborrhoeic dermatitis and tender facial induration

in a chest X-ray (CXR). A sputum examination for AFB was positive and GeneXpert confirmed rifampicin resistance. At that time, she revealed a diagnosis of human immunodeficiency virus (HIV) infection and tuberculous lymphadenitis, which was made 5 years back, where she had taken 6-month TB treatment but had defaulted on antiretroviral therapy. During this presentation, her CD4+ count was $57 / \mu \mathrm{L}$. The rest of the investigations are summarized in Table 1. There was no contact history of leprosy or TB. She was started on a multidrug treatment regime, which included intravenously administered kanamycin (15 mg/kg per day), orally administered ethambutol (800 mg/day), orally administered levofloxacin (750 mg/ day), isoniazid (300 mg/day), orally administered ethionamide (500 mg/day), orally administered cycloserine (750 $\mathrm{mg} /$ day), and orally administered pyridoxine $(10 \mathrm{mg} /$ day $)$. A repeated split skin smear was negative and she continued with multidrug treatment-multibacillary therapy (dapsone $100 \mathrm{mg} /$ day and clofazimine $50 \mathrm{mg} /$ day and $300 \mathrm{mg} /$ once a month) for leprosy without rifampicin. Highly active antiretroviral treatment was restarted subsequently. At 6 months she had clinically, hematologically, and radiologically improved.

\section{Case 2}

A 47-year-old Tamil woman with poorly controlled long-standing diabetes mellitus presented with facial infiltration, multiple ichthyotic patches, and peripheral neuropathy associated with Charcot joints and trophic ulcers (Fig. 2). She was a homemaker with poor social background and there was no contact history of TB or leprosy. She did not smoke tobacco or drink alcohol. She had received a BCG vaccination. She had a low BMI and a respiratory examination revealed $\mathrm{B} / \mathrm{L}$ coarse crepitations. There was no peripheral neuropathy. A clinical diagnosis of lepromatous leprosy was made which was later confirmed with histology and slit-skin smears: bacteriological index (BI) of 5; morphological index (MI) of $2 \%$. Initial investigations revealed persistently elevated ESR (100-122 mm/hour) and inflammatory 
Table 1 Basic investigations of six cases of tuberculosis and leprosy coinfection

\begin{tabular}{|c|c|c|c|c|c|c|c|c|c|c|}
\hline & $\begin{array}{l}\text { WBC } \\
10^{3} / \mu \mathrm{L}\end{array}$ & $\begin{array}{l}\mathrm{Hb} \\
\mathrm{g} / \mathrm{dL}\end{array}$ & $\begin{array}{l}\mathrm{PLT} \\
10^{3} / \mu \mathrm{L}\end{array}$ & $\begin{array}{l}\mathrm{SC} \\
\mathrm{mg} / \mathrm{dL}\end{array}$ & $\begin{array}{l}\text { Sodium } \\
\mathrm{mmol} / \mathrm{L}\end{array}$ & $\begin{array}{l}\text { AST } \\
\text { U/L }\end{array}$ & $\begin{array}{l}\text { ALT } \\
\text { U/L }\end{array}$ & $\begin{array}{l}\text { Alb } \\
\text { g/L }\end{array}$ & $\begin{array}{l}\text { Glob } \\
\text { g/L }\end{array}$ & UFR \\
\hline Case 1 & 3.3 & 10.6 & 150 & 1.13 & 141 & 45 & 50 & 2.6 & 3.0 & Normal \\
\hline Case 2 & 6.0 & 12.3 & 202 & 0.9 & 137 & 35 & 56 & 3.5 & 4.3 & Normal \\
\hline Case 3 & 8.0 & 13.9 & 222 & 1.4 & 138 & 33 & 45 & 3.4 & 3,5 & Normal \\
\hline Case 4 & 6.8 & 11.5 & 230 & 0.9 & 140 & 44 & 54 & 3.0 & 4.2 & Normal \\
\hline Case 5 & 5.7 & 13.2 & 190 & 1.1 & 135 & 60 & 70 & 3.5 & 2.9 & Normal \\
\hline Case 6 & 6.5 & 13.5 & 240 & 1.3 & 137 & 49 & 45 & 3.4 & 3.6 & Normal \\
\hline
\end{tabular}

Alb albumin, ALT alanine transaminase, AST aspartate transaminase, Glob globulin, $H b$ hemoglobin, PLT platelet, SC serum creatinine, UFR urine full report, WBC white blood cells

shadows in a CXR. Two consecutive sputum smears were positive for AFB and the result of a Mantoux test was positive $(18 \mathrm{~mm})$. Her liver and renal functions were normal (Table 1). She was negative for HIV screening. She was commenced on both TB (isoniazid $300 \mathrm{mg} /$ day, rifampicin $450 \mathrm{mg} /$ day, ethambutol $800 \mathrm{mg} /$ day, and pyrazinamide $1500 \mathrm{mg} /$ day) and multibacillary leprosy treatment (dapsone $100 \mathrm{mg} /$ day and clofazimine $50 \mathrm{mg} /$ day and $300 \mathrm{mg} /$ once a month) without a monthly loading dose of rifampicin. She had poor compliance and defaulted treatment several times and ultimately succumbed to the illness. An autopsy was not performed.

\section{Case 3}

A 72-year-old Tamil man presented with a 2-year history of trophic ulcers, auto-amputated fingers, and facial infiltration (Fig. 3). He was a retired mason from a poor social back ground with low income and did not have any other medical diseases. A general examination and neurological examination was normal. There was no significant contact history of leprosy or TB. He had received a BCG vaccination. He was an ex-smoker of tobacco and an ex-drinker of alcohol. His evaluation confirmed the clinical diagnosis of leprosy with highly positive slit-skin smears and histological evidence of lepromatous leprosy. He also gave a history of constitutional symptoms, evening pyrexia, and loss of weight and appetite. His ESR was $113 \mathrm{~mm} /$ hour and a sputum examination revealed AFB along with positive Mantoux test of $14 \mathrm{~mm}$ and CXR evidence of pulmonary TB. Basic investigations are given in Table 1. He was evaluated for both congenital and acquired immunodeficiency status, which did not reveal any abnormality. Although treatment for both conditions was commenced (isoniazid $300 \mathrm{mg} /$ day, rifampicin $450 \mathrm{mg} /$ day, ethambutol $800 \mathrm{mg} /$ day, and pyrazinamide $1500 \mathrm{mg} /$ day and dapsone $100 \mathrm{mg} /$ day and clofazimine $50 \mathrm{mg} /$ day and $300 \mathrm{mg} /$ once a month) in liaison with a respiratory team, he was lost to follow up.

\section{Case 4}

A 59-year-old Sinhalese man presented with nonhealing ulcers and deformities of both upper and lower limbs and indurations of his face (Fig. 4) for many years. He was clinically diagnosed to have borderline lepromatous leprosy, which was subsequently confirmed with slit-skin smears and histology. He was a laborer from poor social background and did not have a significant past medical history. He was emaciated with low BMI; a neurological

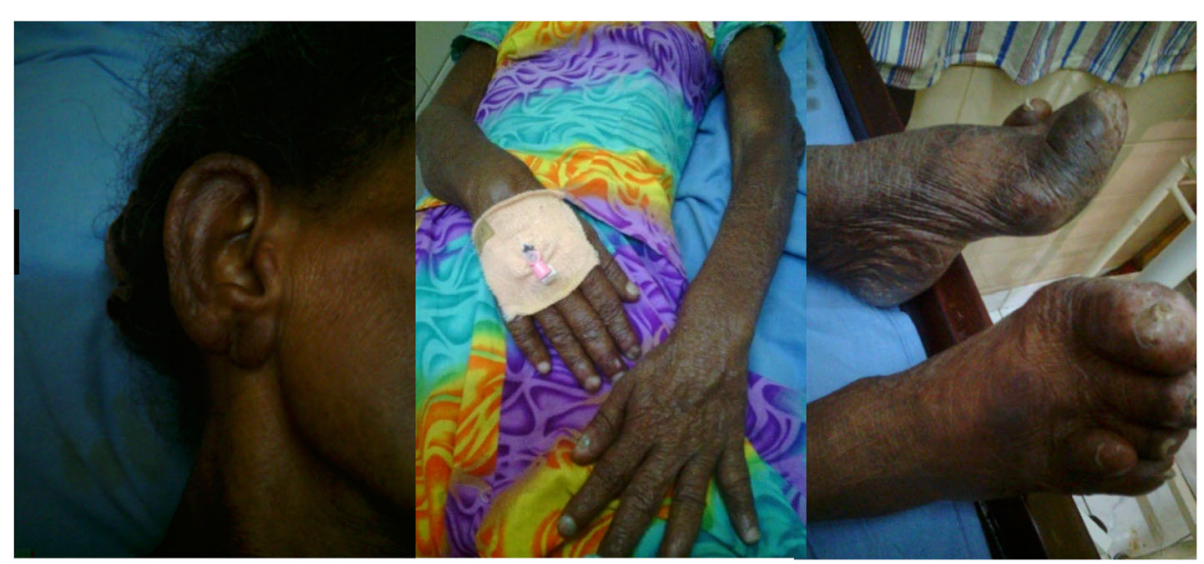

Fig. 2 Facial infiltration, multiple ichthyotic patches, and peripheral neuropathy associated with Charcot joints and trophic ulcers 


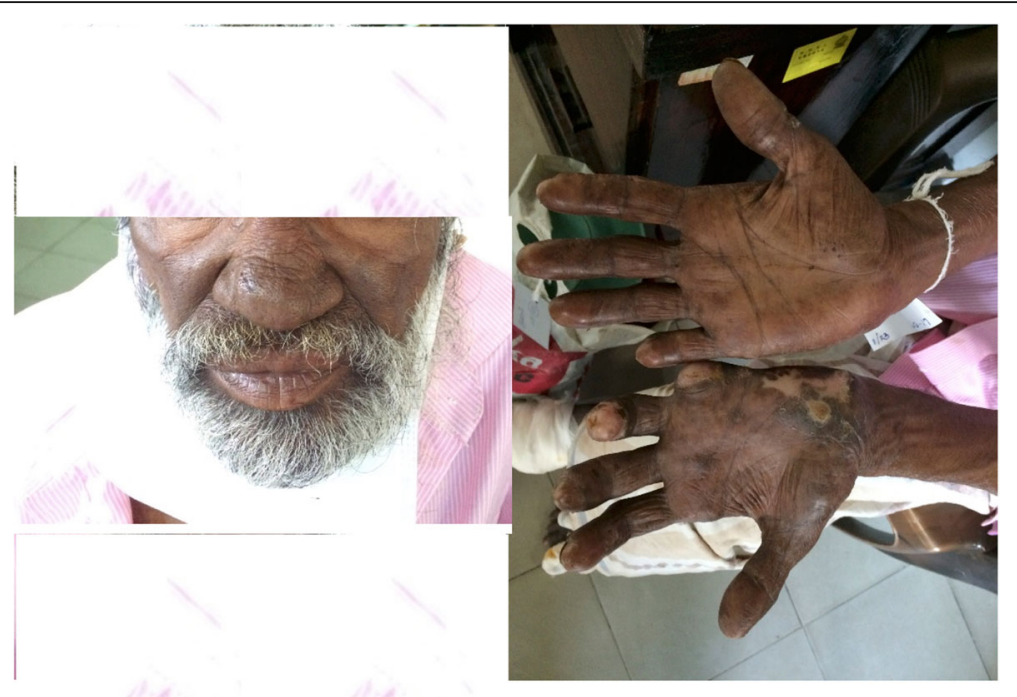

Fig. 3 Trophic ulcers, auto-amputated fingers, and facial infiltration

examination did not reveal neuropathy. There was no contact history of leprosy or TB. He had received a BCG vaccination. He did not smoke tobacco and he drank alcohol occasionally. During his initial evaluation he was also found to have high ESR ( $>100 \mathrm{~mm} /$ hour) with positive Mantoux test $(21 \mathrm{~mm})$ and sputum was positive for AFB. A CXR and contrast-enhanced computer tomography scan of his chest revealed the focus of pulmonary TB; bronchoalveolar lavage for TB culture revealed growth of AFB, but GeneXpert did not reveal rifampicin resistance. His HIV status was negative and repeated blood sugar levels remained within normal range. Other basic investigations are given in Table 1 . He was commenced on multibacillary leprosy treatment (dapsone $100 \mathrm{mg} /$ day and clofazimine $50 \mathrm{mg} /$ day and $300 \mathrm{mg} /$ once a month) and subsequently added TB treatment (isoniazid $300 \mathrm{mg} /$ day, rifampicin $450 \mathrm{mg}$ /day, ethambutol 800 $\mathrm{mg} /$ day, and pyrazinamide $1500 \mathrm{mg} /$ day) for 6 months. At 6 months, his ESR came down, sputum was negative for $\mathrm{AFB}$, and skin lesions and ulcers improved.

\section{Case 5}

A 54-year-old Sinhalese man, an intravenous substance abuser, a tobacco smoker, and alcoholic, who was a garbage truck worker by occupation, with a close contact history of leprosy (his daughter), presented with leonine face and asymptomatic infiltrated papules and plaques over his earlobes of 5 months' duration and hypopigmented hypoanesthetic patches all over his body for a similar duration (Fig. 5). His skin smear and skin biopsy were compatible with borderline lepromatous leprosy. He had a normal BMI; a neurological examination was normal. He had received a BCG vaccination. He was commenced on multibacillary treatment for leprosy

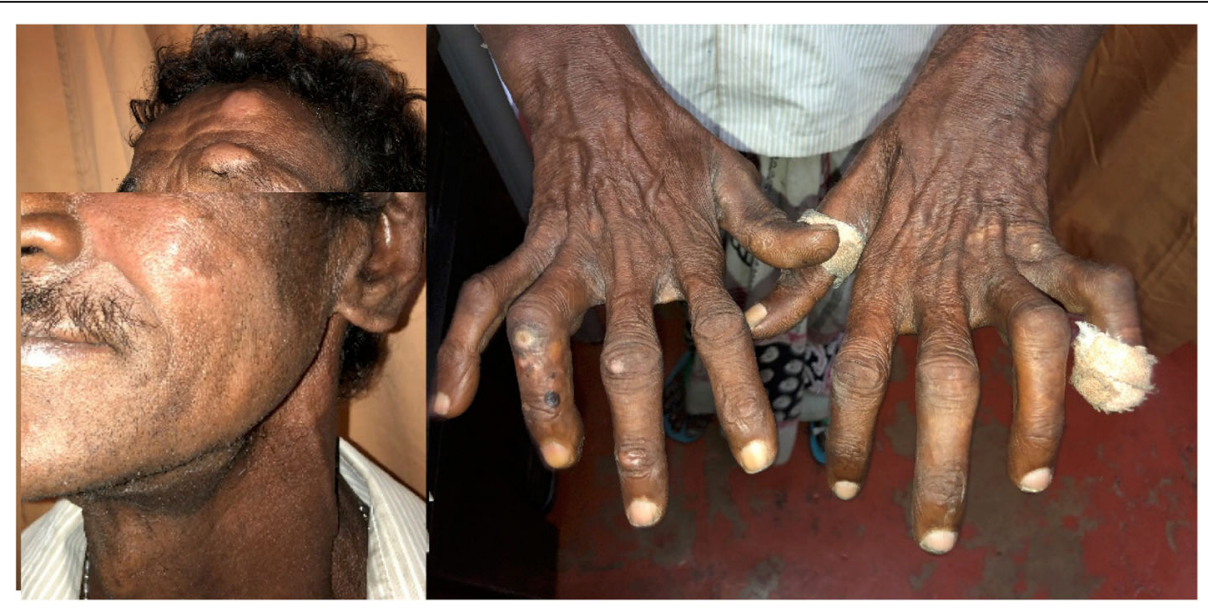

Fig. 4 Nonhealing ulcers, deformities of both upper and lower limbs, and indurations of the face 
(dapsone $100 \mathrm{mg} /$ day, clofazimine $50 \mathrm{mg} /$ day and 300 $\mathrm{mg} /$ once a month and rifampicin $600 \mathrm{mg} /$ month) with tailing-off of dose of prednisolone starting from $40 \mathrm{mg}$ daily. Six months later, he presented with productive cough with nocturnal pyrexia; an evaluation revealed high ESR (130 mm/hour), CXR evidence of active pulmonary $\mathrm{TB}$, and positive sputum smear for AFB. Immune function studies carried out to evaluate his immunodeficiency status did not reveal any congenital or acquired immunodeficiency conditions, including diabetes and HIV. Table 1 gives the basic investigations. He was commenced on TB (isoniazid $300 \mathrm{mg} /$ day, rifampicin $450 \mathrm{mg} /$ day, ethambutol $800 \mathrm{mg} /$ day, and pyrazinamide $1500 \mathrm{mg} /$ day) treatment. He defaulted treatment several times with regards to both leprosy and TB and later died due to TB. An autopsy was not performed.

\section{Case 6}

A 50-year-old Sinhalese man with poorly controlled diabetes mellitus presented with facial infiltration (Fig. 6) and erythematous painful nodules over his lower limbs and trunk suggestive of lepromatous leprosy with erythema nodosum leprosum. He was a manual laborer with low BMI. The rest of the general and neurological examination was normal. He had received a BCG vaccination. He did not smoke tobacco and drank alcohol occasionally. A skin biopsy revealed evidence of foamy macrophages with well-developed grenz zone. He was commenced on multidrug treatment-multibacillary treatment for leprosy (dapsone $100 \mathrm{mg} /$ day, clofazimine $50 \mathrm{mg} /$ day and $300 \mathrm{mg} /$ once a month, and rifampicin $600 \mathrm{mg} / \mathrm{month}$ ) with prednisolone $40 \mathrm{mg}$ daily for type 2 reaction. Twelve months later he developed generalized lymphadenopathy with low-grade evening pyrexia and elevated ESR (80-100 mm/hour). Both Mantoux and
QuantiFERON Gold test were positive. A CXR remained persistently normal. He was negative for HIV and diabetes. Basic investigations are given in Table 1. A lymph node excision biopsy revealed suppurative inflammation with focal foamy histiocytes; a TB culture from the lymph node biopsy later showed growth of AFB. GeneXpert did not reveal rifampicin resistance. Therefore, he was started on TB treatment (isoniazid $300 \mathrm{mg} /$ day, rifampicin $450 \mathrm{mg} /$ day, ethambutol $800 \mathrm{mg} /$ day, and pyrazinamide $1500 \mathrm{mg} /$ day) by the respiratory physician for the treatment of extrapulmonary TB. At 6 months, he had improved clinically and biochemically.

\section{Discussion}

Here we describe six cases of TB and leprosy coinfection (Table 2). TB infection is seen across the entire spectrum of leprosy $[4,5]$. In our case series, three patients had lepromatous leprosy, two patients had borderline tuberculoid leprosy, and one had borderline lepromatous leprosy. Four patients were men and two were women. These findings are similar to the case series of Nigam and colleagues, where out of 20 cases, the majority had lepromatous leprosy and a majority were men [5]. In addition, in the literature, most of the coinfections of TB with leprosy were cases of lepromatous leprosy followed by borderline lepromatous leprosy and only a few cases of tuberculoid type of leprosy $[6,7]$. In the same series of Nigam and colleagues, symptoms of leprosy preceded the symptoms of pulmonary TB and some patients had leprosy for a very long time (10-15 years) before TB [5]. In our series, three patients had leprosy on presentation and were found to have TB during investigations, two patients developed TB later while on treatment for leprosy, and one had a history of extrapulmonary TB 5 years before the diagnosis of leprosy. In

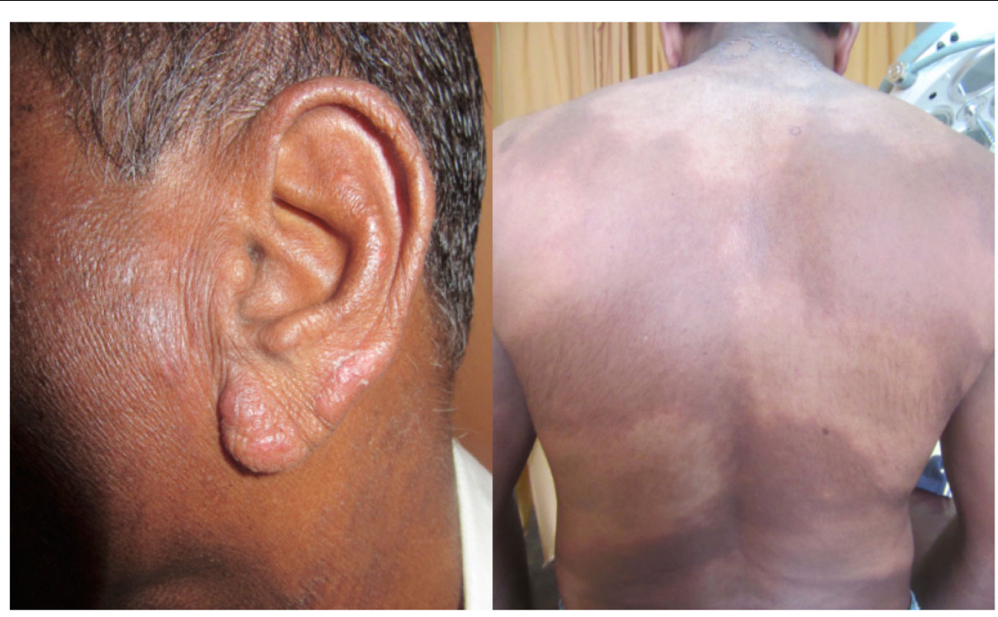

Fig. 5 Asymptomatic infiltrated papules and plaques over the earlobes of 5 months' duration and hypopigmented hypoanesthetic patches all over the body of similar duration 


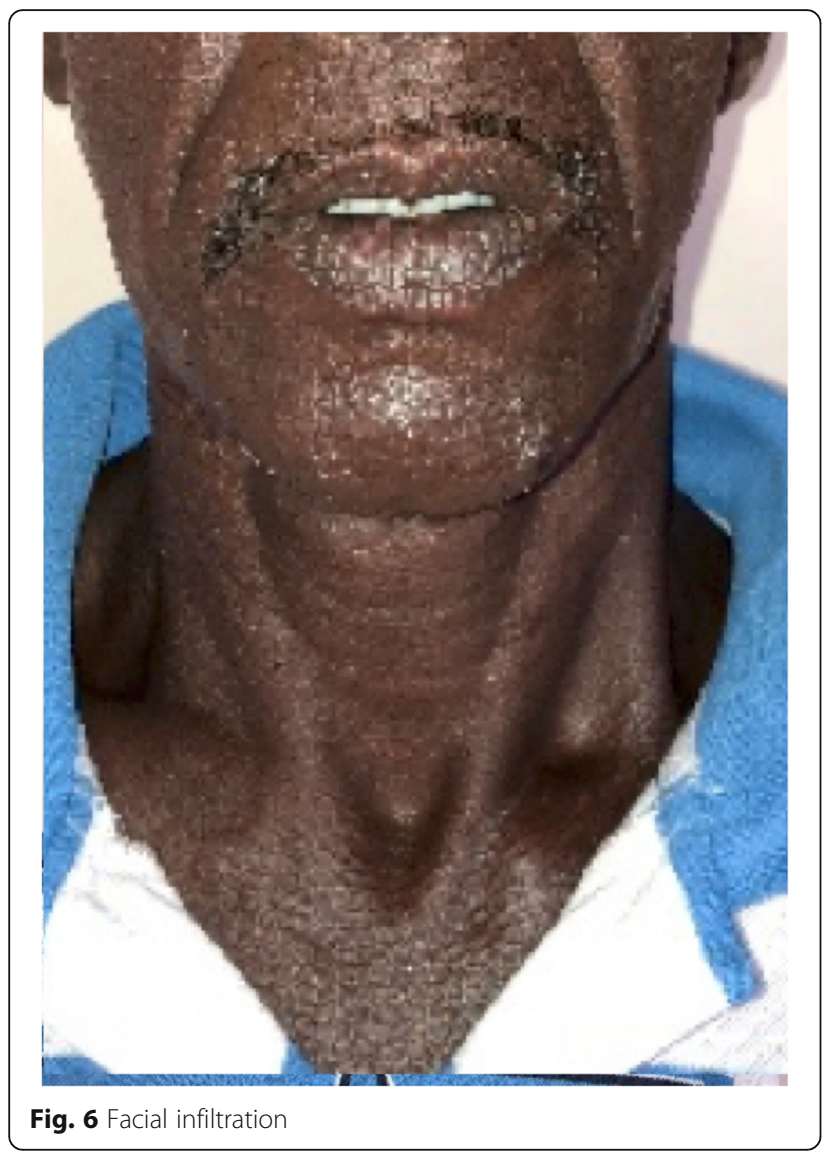

the reported cases, the majority had pulmonary $\mathrm{TB}$, whereas extrapulmonary TB was rare (TB of the larynx in a lepromatous patient [8], cutaneous TB [9], and central nervous system TB [3]). In our series, one patient developed extrapulmonary TB involving generalized lymphadenopathy while on treatment for leprosy. In the cases we report, a majority of our patients with pulmonary TB had positive Mantoux test, high ESR, radiological evidence of TB, and AFB in sputum. Nigam et al. also reported radiological evidence in $70 \%$ of cases and AFB in sputum in $80 \%$ of cases in their case series [5].

Leprosy and TB coinfection in the same patient was first reported in 1954 [10] and later several cases were published in the literature. There is an apparent decline in the number of coinfections [3]. Different theories have been put forward to explain the interaction between leprosy and TB. Some investigators suggested cross-immunity between the two diseases leading to reduced susceptibility to TB in those who have acquired immunity against $M$. leprae. Chaussinand reported that the prevalence of leprosy and the prevalence of $\mathrm{TB}$ are inversely related to each other and that prior $\mathrm{TB}$ exposure can be protective against leprosy [11]. Lietman et al. also suggested that TB could have contributed to the decline of leprosy in Western Europe [12]. Ohara and collegues immunized mice with recombinant Mycobacterium bovis BCG and this has led to reduced multiplication of $M$. leprae in the foot pads of mice, which supports the theory of cross immunity [13]. However, Donoghue et al. argued that multibacillary leprosy has led to increased mortality from TB [14].

Patients immunocompromised due to HIV infection, diabetes mellitus, and immunosuppressive drugs are more susceptible to TB infection. Whether the use of steroids in the treatment of leprosy increases the development of TB is controversial. In this series, two patients were on prednisolone for leprosy when they developed TB. Sreeramareddy et al. [15], Prasad et al. [16], Trindade et al. [1], and Rawson et al. [3] also reported cases of patients who developed TB while they were on steroids for leprosy. Agarwal et al. [17] reported the case of a post renal transplant recipient on a low dose of steroids and azathioprine, who developed both TB and leprosy. Jick et al. concluded that patients treated with glucocorticoids have an increased risk

Table 2 Six cases of tuberculosis and leprosy coinfection

\begin{tabular}{|c|c|c|c|c|c|c|c|}
\hline Patient & $\begin{array}{l}\text { Age } \\
\text { (years) }\end{array}$ & Sex & First infection & Leprosy spectrum & Presentation of tuberculosis & $\begin{array}{l}\text { Time gap between } \\
\text { two infections }\end{array}$ & Comorbidities \\
\hline 1 & 57 & Female & $\begin{array}{l}\text { Extrapulmonary } \\
\text { tuberculosis }\end{array}$ & $\begin{array}{l}\text { Borderline } \\
\text { tuberculoid }\end{array}$ & $\begin{array}{l}\text { Extrapulmonary tuberculosis later } \\
\text { pulmonary tuberculosis }\end{array}$ & 5 years & HIV \\
\hline 2 & 47 & Female & $\begin{array}{l}\text { Simultaneous detection of } \\
\text { both conditions }\end{array}$ & $\begin{array}{l}\text { Lepromatous } \\
\text { leprosy }\end{array}$ & Pulmonary tuberculosis & Simultaneous & Diabetes \\
\hline 3 & 72 & Male & $\begin{array}{l}\text { Simultaneous detection of } \\
\text { both conditions }\end{array}$ & $\begin{array}{l}\text { Lepromatous } \\
\text { leprosy }\end{array}$ & Pulmonary tuberculosis & Simultaneous & \\
\hline 4 & 59 & Male & $\begin{array}{l}\text { Simultaneous detection of } \\
\text { both conditions }\end{array}$ & $\begin{array}{l}\text { Borderline } \\
\text { lepromatous } \\
\text { leprosy }\end{array}$ & Pulmonary tuberculosis & Simultaneous & \\
\hline 5 & 54 & Male & Leprosy & $\begin{array}{l}\text { Borderline } \\
\text { lepromatous } \\
\text { leprosy }\end{array}$ & Pulmonary tuberculosis & 6 months & \\
\hline 6 & 50 & Male & Leprosy & $\begin{array}{l}\text { Lepromatous } \\
\text { leprosy }\end{array}$ & Extrapulmonary tuberculosis & 12 months & Diabetes \\
\hline
\end{tabular}


of developing TB [18]. However, major trials using corticosteroids for prophylaxis and treatment of nerve function impairment in leprosy did not identify steroid use as a risk factor for TB $[19,20]$. Patients with lepromatous leprosy have been demonstrated to have downregulated immune response due to lower tumor necrosis factor (TNF)-alpha and chemokine response [21], which can be a risk factor for the development of TB. Three of our patients had lepromatous leprosy, who developed TB. One had HIV with low CD4 count and another patient had diabetes as possible causes for immunosuppression for both infections.

Development of rifampicin resistance secondary to rifampicin monthly dosing in leprosy can be a major concern in coinfected patients. However, currently there are no case reports of rifampicin resistance identified in coinfected patients in the literature [3]. Our first patient was diagnosed to have rifampicin-resistant TB while she was on treatment for leprosy with rifampicin and she also had HIV infection and a past history of extrapulmonary TB. Kumar et al. stated the importance of recognizing the presence of TB in patients with leprosy to avoid monthly rifampicin to prevent the development of rifampicin-resistant TB [4].

\section{Conclusion}

In this case series of leprosy and TB coinfection, a majority of our patients were men, had lepromatous leprosy, and developed leprosy first and a majority of our patients with pulmonary TB had positive Mantoux test, high ESR, radiological evidence, and AFB in sputum, which is compatible with previously reported cases in the literature. An immunocompromised status, such as HIV infection, diabetes, and immunosuppressive drugs, are risk factors for TB infection. The use of steroids in the treatment of leprosy may increase the susceptibility to develop TB. Development of rifampicin resistance secondary to monthly rifampicin in leprosy is a major concern in treating coinfected patients with TB. Despite the paucity of reports of coinfection, it is advisable to screen for TB in patients with leprosy, especially if there are respiratory or constitutional symptoms, high ESR, and abnormal CXR. Because positive Mantoux and QuantiFERON Gold tests and the presence of AFB in sputum are misleading, CXR evidence of active TB and positive TB cultures are important diagnostic clues for active TB infection in a patient with leprosy. This is important to avoid monthly rifampicin in patients with suspected coinfections, which may lead to development of drug resistance to TB treatment. Whether prolonged steroid therapy in leprosy is a risk factor for development of TB is still controversial.

\section{Abbreviations}

AFB: Acid-fast bacilli; BCG: Bacillus Calmette-Guérin; B/L: Bilateral; BMI: Body mass index; HIV: Human immunodeficiency virus; ESR: Erythrocyte sedimentation rate; CXR: Chest X-ray; TB : Tuberculosis

\section{Acknowledgements}

None to declare.

\section{Authors' contributions}

BSDPK and HMMTBH did the literature survey and prepared the main manuscript. BSDPK, GHDCJ, TB, TJ, TSK, and CNG were involved in the diagnosis and management of the patients. BSDPK, GHDCJ, TB, TJ, and TSK did the data collection. HMMTBH and CNG did the proof reading and correcting of the manuscript. All the authors approved the manuscript.

\section{Funding}

No source of funding.

\section{Availability of data and materials}

The data sets supporting the conclusions of this article are included within the article.

\section{Ethics approval and consent to participate}

Not applicable.

\section{Consent for publication}

Written informed consent was obtained from the patients for publication of this case report and any accompanying images. Copies of the written consents are available for review by the Editor-in-Chief of this journal.

\section{Competing interests}

The authors declare that they have no competing interests.

\section{Author details}

'Dermatology Unit, National Hospital of Sri Lanka, Colombo, Sri Lanka. ${ }^{2}$ Institute of Neurology, National Hospital of Sri Lanka, Colombo, Sri Lanka.

${ }^{3}$ National Hospital of Sri Lanka, Colombo, Sri Lanka.

Received: 9 April 2019 Accepted: 28 May 2020

Published online: 16 July 2020

\section{References}

1. Trindade MA, Miyamoto D, Benard G, Sakai-Valente NY, Vasconcelos Dde M, Naafs B. Leprosy and tuberculosis co-infection: clinical and immunological report of two cases and review of the literature. Am J Trop Med Hyg. 2013; 88(2):236-40.

2. Ridley DS, Jopling WH. Classification of leprosy according to immunity. A five-group system. Int J Lepr Other Mycobact Dis. 1966;34(3):255-73.

3. Rawson TM, Anjum V, Hodgson J, Rao AK, Murthy K, Rao PS, Subbanna J, Rao PV. Leprosy and tuberculosis concomitant infection: a poorly understood, age-old relationship. Lepr Rev. 2014;85(4):288-95.

4. Kumar B, Kaur S, Kataria S, Roy SN. Concomitant occurrence of leprosy and tuberculosis--a clinical, bacteriological and radiological evaluation. Lepr India. 1982;54(4):671-6.

5. Nigam P, Dubey AL, Dayal SG, Goyal BM, Saxena HN, Samuel KC. The association of leprosy and pulmonary tuberculosis. Lepr India. 1979;51(1):65-73.

6. Gupta MC, Prasad M. Associated infection of pulmonary tuberculosis and leprosy. Indian J Med Sci. 1971;25(3):183-5. passim.

7. Gajwani BW, Verma BS, Marwaha RK, Pande RS. Simultaneous infection with M. tuberculosis and M. leprae. J Assoc Physicians India. 1968;16(8):563-4.

8. Flanagan PM, Mcllwain JC. Tuberculosis of the larynx in a lepromatous patient. J Laryngol Otol. 1993;107(9):845-7.

9. Inamadar AC, Sampagavi W. Concomitant occurrence of leprosy, cutaneous tuberculosis and pulmonary tuberculosis-a case report. Lepr Rev. 1994;65(3):282-4.

10. Relvich AL. The treatment of tuberculosis in leprosy patients. Lepr Rev. 1954; 25(4):179-86.

11. Chaussinand R. Tuberculosis and leprosy; mutually antagonistic diseases. Lepr Rev. 1953;24(2):90-4.

12. Lietman T, Porco T, Blower S. Leprosy and tuberculosis: the epidemiological consequences of cross-immunity. Am J Public Health. 1997;87(12):1923-7.

13. Ohara N, Matsuoka M, Nomaguchi H, Naito M, Yamada T. Inhibition of multiplication of Mycobacterium leprae in mouse foot pads by recombinant Bacillus Catmette-Guerin (BCG). Vaccine. 2000;18(14):1294-7.

14. Donoghue HD, Marcsik A, Matheson C, Vernon K, Nuorala E, Molto JE, Greenblatt CL, Spigelman M. Co-infection of Mycobacterium tuberculosis and Mycobacterium leprae in human archaeological samples: a possible 
explanation for the historical decline of leprosy. Proc Biol Sci. 2005; 272(1561):389-94.

15. Sreeramareddy CT, Menezes RG, Kishore P. Concomitant age old infections of mankind - tuberculosis and leprosy: a case report. J Med Case Rep. 2007;1:43.

16. Prasad R, Verma SK, Singh R, Hosmane G. Concomittant pulmonary tuberculosis and borderline leprosy with type-II lepra reaction in single patient. Lung India. 2010;27(1):19-23.

17. Agarwal DK, Mehta AR, Sharma AP, Sural S, Kumar A, Mehta B, et al. Coinfection with leprosy and tuberculosis in a renal transplant recipient. Nephrol Dial Transplant. 2000;15:1720-1.

18. Jick SS, Lieberman ES, Rahman MU, Choi HK. Glucocorticoid use, other associated factors, and the risk of tuberculosis. Arthritis Rheum. 2006;55(1):19-26.

19. Smith WC, Anderson AM, Withington SG, van Brakel WH, Croft RP, Nicholls $\mathrm{PG}$, Richardus JH. Steroid prophylaxis for prevention of nerve function impairment in leprosy: randomised placebo controlled trial (TRIPOD 1). BMJ. 2004:328(7454):1459

20. Richardus JH, Withington SG, Anderson AM, Croft RP, Nicholls PG, Van Brakel WH, Smith WC. Adverse events of standardized regimens of corticosteroids for prophylaxis and treatment of nerve function impairment in leprosy: results from the 'TRIPOD' trials. Lepr Rev. 2003;74(4):319-27.

21. Hasan Z, Jamil B, Zaidi I, Zafar S, Khan AA, Hussain R. Elevated serum CCL2 concomitant with a reduced Mycobacterium-induced response leads to disease dissemination in leprosy. Scand J Immunol. 2006;63(3):241-7.

\section{Publisher's Note}

Springer Nature remains neutral with regard to jurisdictional claims in published maps and institutional affiliations.

Ready to submit your research? Choose BMC and benefit from:

- fast, convenient online submission

- thorough peer review by experienced researchers in your field

- rapid publication on acceptance

- support for research data, including large and complex data types

- gold Open Access which fosters wider collaboration and increased citations

- maximum visibility for your research: over $100 \mathrm{M}$ website views per year

At $\mathrm{BMC}$, research is always in progress.

Learn more biomedcentral.com/submissions 